\title{
A framework for model-based optimization of bioprocesses under uncertainty: Lignocellulosic ethanol production case
}

\author{
Morales Rodriguez, Ricardo; Meyer, Anne S.; Gernaey, Krist; Sin, Gürkan
}

Published in:

Computers \& Chemical Engineering

Link to article, DOI:

10.1016/j.compchemeng.2011.12.004

Publication date:

2012

Document Version

Early version, also known as pre-print

Link back to DTU Orbit

Citation (APA):

Morales Rodriguez, R., Meyer, A. S., Gernaey, K., \& Sin, G. (2012). A framework for model-based optimization of bioprocesses under uncertainty: Lignocellulosic ethanol production case. Computers \& Chemical Engineering, 42, 115-129. https://doi.org/10.1016/j.compchemeng.2011.12.004

\section{General rights}

Copyright and moral rights for the publications made accessible in the public portal are retained by the authors and/or other copyright owners and it is a condition of accessing publications that users recognise and abide by the legal requirements associated with these rights.

- Users may download and print one copy of any publication from the public portal for the purpose of private study or research.

- You may not further distribute the material or use it for any profit-making activity or commercial gain

- You may freely distribute the URL identifying the publication in the public portal 


\title{
A framework for model-based optimization of
}

\section{bioprocesses under uncertainty: Lignocellulosic}

\section{ethanol production case}

\author{
Ricardo Morales-Rodriguez $^{\mathrm{a}}$, Anne S. Meyer ${ }^{\mathrm{b}}$, Krist V. Gernaey ${ }^{\mathrm{c}}$, Gürkan Sin $^{\mathrm{a}^{*}}$ \\ ${ }^{a}$ CAPEC, Dept. of Chemical and Biochemical Engineering, Technical University of \\ Denmark, DK-2800 Lyngby, Denmark, * corresponding author: gsi@kt.dtu.dk. \\ ${ }^{\mathrm{b}}$ Center of Bioprocess Engineering, Dept. of Chemical and Biochemical Engineering, \\ Technical University of Denmark, DK-2800 Lyngby, Denmark \\ ${ }^{c}$ Center for Process Engineering and Technology, Dept. of Chemical and Biochemical \\ Engineering, Technical University of Denmark, DK-2800 Lyngby, Denmark.
}

\begin{abstract}
:
This study presents the development and application of a systematic model-based framework for bioprocess optimization. The framework relies on the identification of sources of uncertainties via global sensitivity analysis, followed by the quantification of their impact on performance evaluation metrics via uncertainty analysis. Finally, stochastic programming is applied to drive the process development efforts forward subject to these uncertainties. The framework is evaluated on four different process configurations for cellulosic ethanol production including Simultaneous Saccharification and Co-Fermentation and Separate Hydrolysis and Co-Fermentation (SSCF and SHCF, respectively) technologies in different operation modes (continuous and continuous with recycle). The results showed that parameters related to pretreatment (e.g. activation energy of the reaction for glucose production, order of reaction, etc.), hydrolysis (inhibition constant for xylose on conversion of cellulose and cellobiose, etc) and co-fermentation (ethanol yield on xylose, inhibition constant on
\end{abstract}


microbial growth, etc.), are the most significant sources of uncertainties affecting the unit production cost of ethanol with a standard deviation of up to $0.13 \mathrm{USD} /$ gal-ethanol. Further stochastic optimization demonstrated the options for further reduction of the production costs with different processing configurations, reaching a reduction of up to $28 \%$ in the production cost in the SHCF configuration compared to the base case operation. Further, the framework evaluated here for uncertainties in the technical domain, can also be used to evaluate the impact of market uncertainties (feedstock prices, selling price of ethanol, etc) and political uncertainties (such as subsidies) on the economic feasibility of lignocellulosic ethanol production.

Keywords: Uncertainty analysis, sensitivity analysis, stochastic optimization, bioethanol production, Monte-Carlo simulations

\section{Introduction}

Process optimization is an important area within process systems engineering (PSE), actively used in the development, decision making, and subsequent improvement of chemical processes (e.g. for the design, synthesis and operation), aiming at maximizing the process performance while at the same time minimizing the processing costs (Grossmann \& Guillén-Gonsálbez, 2010). Many mathematical programming techniques are applied in process optimization, such as nonlinear programming, mixed-integer nonlinear programming, multi-objective optimization, quadratic programming, among others (Shapiro, Dentcheva, \& Ruszczyński, 2009).

In reality the above-mentioned programming techniques can be further complicated by several sources of uncertainties that can be encountered in practice when solving 
optimization problems, where the variability of uncertain parameters is commonly neglected (Acevedo \& Pistikopoulos (1996); Grossmann \& Guillén-Gonsálbez (2010)). The process optimization is a particularly challenging task in (bio)process development, notably in processes such as cellulosic bioethanol production because several processing configuration options are available and the plant operation is characterized by tight cost and yield margins. In addition, the uncertainties present in the system as a result of technological factors and, economical factors as well as the uncertainty in the mathematical model and parameters employed to perform the optimization task pose severe challenges. A number of publications concerning optimization under uncertainty are available, covering a range of topics, such as process synthesis, design and control under uncertainty (Acevedo \& Pistikopoulos (1996); Pintarič \& Kravanja (2008); Ricardez-Sandoval, Douglas, \& Budman (2011)), planning under uncertainty (Hansen, Grunow, \& Gani, 2011), uncertainty on scheduling (Wang \& Rong, 2010), strategic and global supply chain networks (Verderame \& Floudas (2011); You \& Grossmann (2008)), etc. Most of those publications, when addressing the uncertainty of the optimization problem, have focused on the operational parameters and external sources of uncertainties, for example, product demand and uncertainty on raw material availability.

As far as bioethanol production is concerned, optimization techniques have also been implemented with the aim of optimizing the production using deterministic approaches, which ignores the sources of uncertainties of the production process. The publications have mainly focused on reducing production cost (Karuppiah, Peschel, Grossmann, Martín, Martinson, \& Zullo, 2008), optimization of water consumption (Martín, Ahmetovič, \& Grossmann, 2011), or identifying the optimal processing route for a 
biorefinery with ethanol as product (Zondervan, Nawaz, de Haan, Woodley, \& Gani (2011); Bao, Ng, Tay, Jiménez-Gutiérrez, \& El-Halwagi (2011); Alvarado-Morales, Terra, Gernaey, Woodley, \& Gani, (2009)) .

Some studies such as Kasaš, Kravajna, \& Pintarič (2011) considered uncertainties and have performed stochastic optimization for bioethanol production with the aim of finding a flexible process flowsheet. However, the uncertainties related to the parameters characterizing the processing and separation technologies involved in bioethanol production are rarely considered. This in turn may lead to underestimation of the uncertainties in the prediction of key performance indices of bioprocesses such as yield and unit production cost. To address these uncertainties, it is required to perform a formal and thorough uncertainty and sensitivity analysis.

Therefore, the objective of this paper is to develop a systematic framework for the optimization of bioprocesses subject to various sources of uncertainties. The framework is evaluated on a case study focusing on lignocellulosic bioethanol production. The problem statement in this case study is formulated as follows: given a process flowsheet, an operational configuration and feedstock composition, how can an engineer predict and identify the uncertainty of the main performance criteria considered in plant design and further optimize the performance metrics - e.g. bioethanol yield and concentration, water recovery, energy consumption, operational cost, among others? The process consists of four main operation steps: acid pre-treatment, enzymatic hydrolysis, fermentation and downstream processes. Four different process configurations are investigated: 1. Simultaneous Saccharification and Co-Fermentation in Continuous operation with Recycle of solids (SSCF-C_RECY), 2. Simultaneous Saccharification and Co-Fermentation in Continuous operation (SSCF-C), 3. Separate 
Hydrolysis and Co-Fermentation in Continuous operation with Recycle for both unit operations (SHCF with double recycle), and 4. Separate Hydrolysis and CoFermentation working in continuous mode with recycle for the first unit operation while continuous operation is applied to the co-fermentation reactor (SHCF with single recycle).

\section{A framework for model-based process optimization under}

\section{uncertainty}

The systematic framework for model-based optimization under uncertainty illustrated in

Figure 1, consists of 5 main steps and several sub-steps which guide the user in solving a stochastic optimization problem. The framework includes a number of methods and tools such as the Monte-Carlo method for uncertainty analysis, global techniques for sensitivity analysis and Monte-Carlo based stochastic optimization (Figure 2).

\subsection{Systematic Model-Based Framework for Optimization under Uncertainty}

\subsubsection{Objective and Needs}

The systematic model-based optimization framework starts with the definition of the optimization objective, such as, the yield requirement from the raw materials, a productivity enhancement, a reduction in the production cost, among others.

\subsubsection{Process Configurations and Modelling}

The process model development step involves the collection, analysis and identification of the reliable mathematical models for the different sections of the bioprocess configurations selected for the study. If a suitable overarching model is not available, it is necessary to direct a substantial effort towards generating and validating the required sub-parts of the model, which in itself needs a focused, systematic and structured 
approach including model identification and uncertainty analysis techniques addressed specifically in Sin et al. (2010). In certain cases data may be scarce, difficult to obtain and/or the available data may be encumbered with great uncertainties, and in such cases new experimental data may have to be produced. Following this step, different process flowsheets are generated and implemented in simulation software, with the aim of analyzing and selecting the best process configuration according to the optimization objective (Morales-Rodriguez, Meyer, Gernaey, \& Sin (2011a); Morales-Rodriguez, Meyer, Gernaey, \& Sin (2011b)).

\subsubsection{Screen and Identify significant Sources of Uncertainties}

In the third step, the uncertainty and sensitivity analysis are performed to identify the critical process operational variables and parameters in the system affecting the selected performance criteria. An important element here is the identification of sources of uncertainties in the system. The uncertainty analysis is carried out using the MonteCarlo technique, which involves four steps (see Figure 2): (i) specification of input uncertainty, (ii) sampling of (uncertain) parameters (Latin Hypercube Sampling, LHS) where it is in fact very important to consider the correlations between the parameters of the original model, in order to increase the reliability of the sampling procedure, (iii) Monte-Carlo simulations with the sampled parameter values and (iv) representation of uncertainty (e.g. mean, standard deviation, variance, percentile (Helton \& Davis, 2003)).

For the sensitivity analysis, the standardized regression coefficient (SRC) method is chosen as it provides a good approximation to a global sensitivity measure with an affordable computational demand compared with more computational exhaustive global sensitivity analysis methods such as FAST or Sobol's sensitivity indices (Sin, Gernaey, 
\& Lantz, 2009). The SRC method involves building linear regression models on the output of the Monte-Carlo simulations (Helton \& Davis, 2003). For each model output, a linear multivariate model is fitted to the (scalar) output of the Monte Carlo simulations relating model output $y$ to uncertain parameter vectors, $\theta_{i}$ :

$$
y_{\text {reg }}=a+\sum_{i} b_{i} \cdot \theta_{i}
$$

To obtain the standardised regression coefficients, $\beta_{i}$, the regression coefficients $b_{i}$ are scaled using the standard deviations of uncertain parameters and output of the Monte-

Carlo simulations, $\beta_{i}=\left(\sigma_{\theta_{i}} / \sigma_{y}\right) \cdot b_{i}$. The SRC method provides a global sensitivity measure, $\beta_{i}$, which is a quantitative measure of how much each parameter contributes to the variance (uncertainty) of the model predictions. This sensitivity measure is then used as basis to identify and select the most critical parameters involved in the process. The main goal of performing the sensitivity analysis is that the complexity of the stochastic optimization problem (step 4, see 2.1.4) can be reduced by concentrating the effort just on the parameters which are most influential - or ranking highest - on the outputs of the process model.

\subsubsection{Optimization under Uncertainty}

In the fourth step, a stochastic process optimization study is carried out. The generic mathematical form of the optimization problem is as shown in Eq. (2) (Kleywegt, Shapiro, \& Homem-de-Mello, 2001): 


$$
\min _{x}\left\{Z(x)=c^{T} \mathbf{x}+\mathbf{E}_{s}\left[\mathbf{f}\left(x, \theta_{i}\right)\right]\right\}
$$

st.

$$
\begin{aligned}
& \mathbf{h}(x)=0 \\
& \mathbf{g}(x) \leq \mathbf{d}_{l} \\
& \theta_{i}^{L B} \leq \theta_{i} \leq \theta_{i}^{U B}
\end{aligned}
$$

The objective function is composed of a deterministic term on the one hand $\left(c^{T} \mathbf{x}\right.$, where $c^{T}$ represents a constant vector of economic information and $\mathbf{x}$ is the vector of continuous variables) and an uncertain term $\left(\mathbf{f}\left(x, \theta_{i}\right)\right)$ on the other hand, of which the expected value $\mathbf{E}_{s}\left[\mathbf{f}\left(x, \theta_{i}\right)\right]$ is used to represent the uncertainty as a function of the optimization variables and uncertain parameters $\left(\theta_{i}\right)$. For $\theta_{i}, i$ indicates the $i^{\text {th }}$ uncertain parameter, whose value is located between an upper and lower boundary ( $\theta_{i}^{U B}$ and $\theta_{i}^{L B}$, respectively). $\mathbf{h}$ is the vector of equality constraints and $\mathbf{g}$ is the set of inequality constraints.

While a standard multivariable stochastic optimization method can be used (e.g., formulation of deterministic equivalents of stochastic programming problems and then employ linear vs. non-linear programming solvers), this study proposes a Monte-Carlo based procedure as a pragmatic tool to this end since the sampling is global rather than local thereby reducing the tendency to be entrapped in a local minimum and avoiding a dependency on an assumed set of initial conditions (Gallagher \& Sambridge, (1994); Shapiro, Dentcheva, \& Ruszczyński, (2009)). The first sub-step in the optimization step is the outer loop that performs sampling (e.g., Latin Hypercube Sampling) from a highdimensional operation space, which is formed by a matrix of operating variables with a length of $\mathrm{N}$ resulting in a N-by-N dimensional space. Then, in the inner loop, a Monte- 
Carlo simulation is performed using sampling from the uncertain parameter (identified in section 2.1.3) space to estimate the uncertainty of model outputs used in the objective function calculation (Figure 2). The results from the outer loop Monte-Carlo simulations are then evaluated in order to identify the optimal operation scenario. The evaluation includes statistical descriptors such as, standard deviation, variance and percentiles of the objective function values.

A further refining step can be performed as well, for example if one is not completely satisfied with the result of the Monte-Carlo simulations, by employing the optimization results from the Monte-Carlo simulations as initial guess using the sample average approximation (SAA) method (Kleywegt, Shapiro, \& Homem-de-Mello, 2001), as illustrated in Eq. (3).

$$
\min _{x}\left\{Z(x)=c^{T} \mathbf{x}+N P^{-1} \sum_{i=1}^{N P} f\left(x, \theta_{i}\right)\right\}
$$

This method consists of evaluating the cost optimization function NP (with NP = number of parameters of the evaluated unit operation under study) by employing the parameter samples $\left(\theta_{i}\right)$ and current values of optimization variables $(x)$, to obtain an average cost function that is an approximation of the expected value $\left(\mathbf{E}_{s}\left[\mathbf{f}\left(x, \theta_{i}\right)\right]\right)$ of Eq.(2) into a discrete form, which is subsequently optimized by well-known deterministic optimization methods such as sequential quadratic programming, to name one example. The final results of this step will then provide the optimized operational values under an uncertainty scheme. 


\subsubsection{Validation of Optimal Process Operation}

In step 5, one evaluates the performance of the optimized process operation via comparison to data obtained in lab or pilot-scale or demo-scale experiments. If the validation results are satisfactory, then the systematic procedure will be terminated by accepting the optimal operation scenario results for further implementation in demonstration or production scale. Otherwise the procedure needs to be re-iterated, either by reviewing the mathematical models used for the optimization or by evaluating different sets of critical system parameters. By sequentially applying the optimization procedure to different process configurations, one opens up the possibility to compare different process configurations.

\subsection{Process Characteristics Data and Simulation Platform}

The model implementation, the simulations and the uncertainty and sensitivity analysis have all been performed in Matlab (The Mathworks, Natick, Massachusetts). The basic process characteristics and information regarding conversion rates and dimensions of key unit operations are from (Aden et al. (2002) and Humbird et al. (2011)), but were expanded for dynamic modelling with specific rate equations for enzyme and cofermentations kinetics as outlined in Morales-Rodriguez, Gernaey, Meyer, \& Sin, (2011). Process economic calculations were performed relying on previously published values for feedstock, additives (enzyme and sulphuric acid) and utilities (cooling water and steam) used in the production process (Alvarado-Morales, Terra, Gernaey, Woodley, \& Gani, 2009). 


\section{Results}

\subsection{Evaluation of the Systematic Model-Based Framework for Optimization under Uncertainty}

\subsubsection{Step 1: Objective and Needs}

The objective is to identify the optimal operational boundaries considering uncertainties in the key unit operations for the lignocellulosic ethanol production case study, with the intention to reduce the manufacturing cost per gallon of produced ethanol. This manufacturing cost is broken down into contributions related to feedstock (Feedstock), utilities (Utilities) used in the production process (cooling water and steam in the streams and unit operations to keep the correct operating conditions) and the cost of the employed additives (Additives) (such as, enzyme and acid loading). Thus, the objective function can be written as follows (Eq. (4)):

$$
\min _{x} Z(x)=c_{F S} \text { Feedstock }\left(\theta_{i}\right)+c_{U T} \operatorname{Utilities}\left(x, \theta_{i}\right)+c_{A D D} \text { Additives }\left(x, \theta_{i}\right)[=] \frac{\text { USD }}{\text { gal Ethanol }}
$$

where $c_{F S}$ is the cost of the feedstock $(0.03 \mathrm{USD} / \mathrm{kg}), c_{U T}$ are the costs of utilities (lowpressure steam (0.0075 USD/kg), high-pressure steam (0.0094 USD/kg) and cooling water $(0.0002 \mathrm{USD} / \mathrm{kg}))$ and $c_{A D D}$ are the cost of additives (sulfuric acid (0.085 USD/kg) and enzymes (1.85 USD/kg) (Alvarado-Morales, Terra, Gernaey, Woodley, \& Gani, 2009)).

\subsubsection{Step 2: Process Configurations and Modelling}

Collection of data and implementation of process models (for each unit in the process) of the integrated system has been described previously by Morales-Rodriguez, Meyer, Gernaey \& Sin (2011b). 
The systematic model-based optimization framework for optimization under uncertainty was tested using the Dynamic Lignocellulosic Bioethanol model version 1.0 (DLB1.0) as illustrated in Table A.1, A.2 and A.3 for pretreatment, enzymatic hydrolysis and cofermentation, respectively (Morales-Rodriguez, Meyer, Gernaey, \& Sin, 2011b), which was extended further by adding a rigorous dynamic downstream process (distillation) model (Seader \& Henley, 2006) using the Wilson equation for activity coefficient calculations (Smith, Van Ness, \& Abbott, 2001), and also including heat exchangers and their corresponding energy balances (see Figure 3) to enable calculation of utility consumption such as cooling water and steam. The resulting dynamic plant-wide model was then employed to identify the operational window under uncertainty to assess the operational cost of the conversion of lignocellulose to ethanol. A process configuration involving simultaneous saccharification and co-fermentation operating in a continuous

process (SSCF-C) was selected to be evaluated as base case to highlight the application of the framework.

\subsubsection{Step 3: Screen and Identify significant Sources of Uncertainties}

\subsubsection{Identification of the Sources of Uncertainties}

The complete set of kinetic parameters characterising the pretreatment and SSCF mathematical models (Morales-Rodriguez, Meyer, Gernaey, \& Sin, 2011b) in addition to the feedstock composition were included in the list of potential sources of uncertainties, which resulted in a total of 80 parameters. Their uncertainties may come from changing feedstock composition, experimental procedures used to estimate parameter values, measurement accuracy, changes in enzymatic and microorganism activities, among others. Table A.1 lists the total number of parameters analyzed in this 
study as well as the ranges around the default values which were used as the input uncertainties for the individual model parameters.

\subsubsection{Uncertainty Analysis based on the Monte-Carlo Procedure}

The first screening was performed for the quantification of the uncertainties of the model parameters on model outputs. The sampling of uncertain parameters was accomplished using the LHS method, for which 250 was deemed a sufficient sampling number $(N P)$ based on the calculation of the Monte-Carlo integration error $($ MCerr $=\sigma / \sqrt{N P})$. The Iman-Conover method was used for taking into account the correlation between the uncertain parameters (Iman \& Conover, 1982). To this end, the correlation matrix for the parameters for enzymatic hydrolysis was obtained from previous work (Sin, Meyer, \& Gernaey, 2010), while for pretreatment and cofermentation models the parameter correlations were obtained by re-estimating model parameters on the basis of original publications (Krishnan, Ho \& Tsao (1999) and Lavarack, Griffin \& Rodman (2002), respectively). Subsequently, Monte-Carlo simulations were performed with the sampled parameter values (as illustrated in Figure 2), and the results in the form of key performance indices (KPI) were plotted as histograms (see Figure 4). The uncertainty can be inferred from the variance of these histograms. For example for the base case process configuration, the average production cost is calculated to be $1.56 \mathrm{USD} / \mathrm{gal}$ ethanol with a standard deviation (indicating degree of uncertainty) as \pm 0.13 USD/gal-Ethanol. These results typically show the extent of technical uncertainties on the estimated unit production costs, which must be considered as relatively high (standard deviation is around $10 \%$ of the average unit cost). 


\subsubsection{Sensitivity Analysis: Regression-Based (SRC)}

For the sensitivity analysis, the standardized regression coefficient (SRC) method was used and the aim was to find out which of the uncertain parameters contributed most to the uncertainty in the production cost. Figure 5 illustrates the linear model fitted to Monte-Carlo simulation outputs as a function of the uncertain parameters. Notice that the linear model determination coefficient $\left(\mathrm{R}^{2}\right)$ is equal to 0.85 , meaning that the timeaveraged model outputs could be linearized to a high degree, hence satisfying the requirement for $\beta_{i}$ to be used as a reliable index of the sensitivity measure (threshold $=$ $\left.\mathrm{R}^{2}>0.7\right)$

\subsubsection{Identification of the most critical parameters.}

Based on the SRC results, Table 1 illustrates that 19 out of 80 parameters were found most critical, i.e. significantly affecting the uncertainty on the production cost of ethanol. This also shows that the highest uncertainty is introduced by the model parameters employed in the SSCF unit operation, which is obvious because the main core of this configuration is the conversion of cellulose into glucose and the conversion of glucose and xylose to ethanol. The uncertainty in pretreatment parameters and feedstock composition also rank high, albeit that the model outputs are less sensitive to those parameters compared to the parameters of the SSCF.

More valuable information can be obtained from Table 1 related to the values and signs of the SRC values. For example, the inhibition coefficients for microorganism growth

by glucose $\left(K_{1 X_{G} I G}^{C F}\right)$ and xylose $\left(K_{2 X_{X y} I X y}^{C F}\right)$ (rank 2 and 3, respectively) are negative meaning that decreasing the values of the inhibition coefficients will increase the unit production cost. To decrease the unit production cost, therefore, the values of inhibition 
coefficients should be increased meaning that the microorganisms should be engineered to become more inhibition tolerant in order to reduce the operational cost of bioethanol production. This is a logic conclusion, from a process point of view.

Similarly, performing the same analysis for the reaction rate coefficient from cellulose conversion into sugar $\left(k_{2, G}^{E H}\right)$, it is possible to assume that a higher value of this reaction rate coefficient would decrease the unit production cost. From the phenomenological point of view this shows that an improvement on enzyme performance through protein engineering could also reduce the production cost for bioethanol, which is obviously due to the fact that a higher conversion rate of enzyme catalysed conversion of cellulose into glucose would result in availability of more glucose to be converted into ethanol (all other things being equal). Both of these conclusions are in agreement with the experimental efforts focusing on protein and process engineering to improve the feasibility of lignocellulosic ethanol processes. However, the added value of the uncertainty and sensitivity analysis method shown here is that it quantifies how much potential reduction in the unit production cost can be obtained as a consequence of improvement in enzyme efficiency (or bioreactor design efficiency enhancing the enzyme efficiency), thereby providing a rational basis for process improvements.

\subsubsection{Step 4: Optimization under Uncertainty}

Once sensitivity measures have identified the significant sources of uncertainties in the process, the following step is to find out the optimal operating conditions with the aim of reducing the unit production cost. The implementation of the Monte-Carlo optimization under uncertainty algorithm is illustrated in Figure 6. 


\subsubsection{Sampling from operation space}

First of all, the selection of the important operating variables was done in this step. For the pretreatment, reactor temperature $\left(T_{P T}\right)$ and acid concentration $\left(C_{A c i d}\right)$ were selected, while for the SSCF units enzyme loading of exo- $\beta$-1,4-cellobiohydrolase + endo- $\beta-1,4$ glucanase $\left(E L_{1}\right)$ and $\beta$-glucosidase $\left(E L_{2}\right)$, yeast loading $\left(C_{\text {yeast }}\right)$ and reactor temperature ( $\left.T_{S S C F}\right)$ were chosen as variables to be optimized. In the downstream processes pressure set-points in the reboiler and condenser ( $P_{R, D k}, P_{C, D k}$, respectively) of the distillation columns were the design variables to be optimized, and the water content in the solid stream of the separator $\left(\%_{\mathrm{H} 2 \mathrm{O}}\right)$ was the variable to be optimized in the solid-liquid separator units. Afterwards, the sampling of the operating variables as well as the shortlist of uncertain parameters was performed using LHS. This resulted in a sampling matrix of 150x19, where rows correspond to the LHS samples of the parameters and columns corresponded to the most influential parameters identified previously.

\subsubsection{Monte-Carlo Simulations}

Subsequently a robust Monte-Carlo stochastic optimization was performed with sampled operating variables and parameters values resulting in 100x150 process model evaluations, that is, each of the 100 operating conditions that was sampled was evaluated with the 150 parameter samples. Subsequently, the mean and the $95^{\text {th }}$ percentile values (providing 95\% confidence interval of the estimated unit production cost) were calculated for the 150 samples, and this procedure was repeated for each operating condition (100 samples). These statistical indicators were then employed to determine the optimal set of operating variables under an uncertainty scheme by employing Monte-Carlo simulations. 


\subsubsection{Identification of Feasible Operating Conditions Based on Statistical Techniques}

Based on the mean value and $95 \%$ confidence intervals of production cost, each operation scenario was ranked to identify the optimal operation scenario which will correspond to low production cost with narrow uncertainty range (narrow 95\% confidence interval).

Table 2 summarizes the most feasible operating conditions yielding a lower production cost than the base case. The 95\% confidence interval was selected as performance criterion rather than only the mean value because this measure considers the total number of outputs of the process model evaluated with the parameter samples under uncertainty. For instance, if the selection of the optimal operating conditions relies on comparing only the mean value of the manufacturing cost, the decision for the optimal set of variables would point towards operation scenario number 45 with a $6.23 \%$ lower manufacturing cost, and not to operation scenario 67 with 5.3\% lower manufacturing cost. This is not entirely correct since the use of the mean as a performance measure does not take into account the uncertainties of the parameters in the process.

Therefore, the $95^{\text {th }}$ percentile meaning 95\% confidence (the lower value, the better) was taken as performance criterion for selecting the optimal operation scenario, which revealed that operation scenario number 67 is the optimal result which can reduce the manufacturing cost by more than $8 \%$ compared with the base case scenario. Thus, the resulting optimal operational conditions from Monte-Carlo stochastic optimization are illustrated in Table 3. The comparison of the optimal operational conditions with respect to the base case illustrates a significant reduction of the additives loading and the temperatures in the pretreatment and SSCF reactors, which is reflected in the lower production cost. 
A detailed analysis, section by section, reveals that the new operating conditions result in an $18.5 \%$ saving in the cost of steam in the pretreatment reactor compared with the base case. For the acid loading the expenses are reduced by $33.5 \%$ as a result of diminishing the acid concentration in the pretreatment reactor.

In the SSCF unit operation, the cost of enzymes is reduced by $11.5 \%$ because the amount of enzyme needed for hydrolysis is reduced. Other expenses in the utilities are not different since the operating temperature of the SSCF unit is quite similar to the base case operation.

The utility cost in the downstream processes was decreased by $3.1 \%$ in the first distillation column, while the expenses for the second distillation column were decreased by about $1.6 \%$ with respect to the base case.

Hence, based on these results one can conclude that there is an important potential reduction of the production cost of bioethanol and that the presented framework was able to achieve this. It is important to note that the framework can be used to study the whole process plant or individual sections of the process plant, which in either case provides insights and ideas for reducing the production cost of bioethanol even further.

\subsection{Systematic Model-Based Framework for optimization under Uncertainty:} SSCF-C_RECY, SHCF with double recycle and SHCF with single recycle

\section{configurations.}

The framework for optimization under uncertainty was also implemented for the extended version of the process configurations presented by Morales-Rodriguez, Meyer, Gernaey, \& Sin (2011b) such as, simultaneous saccharification and co-fermentation operating in continuous mode with recycle of solids in the SSCF unit (SSCF-C_RECY), 
separate hydrolysis and co-fermentation working in continuous mode with recycle for both unit operations (SHCF with double recycle) and separate hydrolysis and cofermentation working in continuous mode with recycle for the first unit operation while continuous operation is applied to the co-fermentation reactor (SHCF with single recycle) as illustrated in Figure 7a, Figure 7b and Figure 7c, respectively.

\subsubsection{Screen and Identify significant Sources of Uncertainties: SSCF-C-RECY,} SHCF with double recycle and SHCF with single recycle.

Table 4 summarizes the uncertainty and sensitivity analysis results. The variance is used as the indicator for the degree of uncertainty of the production cost of different process configurations. The results show that the highest uncertainty is found for the SHCF with single recycle configuration followed by the SHCF with double recycle and the SSCFC_RECY.

The sensitivity analysis results are also illustrated in Table 4 where the parameters which propagate significant uncertainty to the outputs of the model are highlighted. The most significant parameters are mostly similar for the three different analyzed configurations in this section, as well as for the SSCF-C configuration described in section 3.1. It was found that the parameters of the co-fermentation kinetics introduce the highest uncertainty in the results of the plantwide simulation for production cost. Indeed, the conversion of the five and six carbon sugars into ethanol is predicted in this section, and the amount of produced ethanol in this section affects the manufacturing cost directly. This also illustrates that it will probably pay off to invest efforts on improving the sugar conversion aiming at increasing the bioethanol production with the same production resources (additives, utilities, etc.), thus resulting in a lower manufacturing cost. 


\subsubsection{Optimization under Uncertainty: SSCF-C_RECY, SHCF with double}

recycle and SHCF with single recycle.

The results from the Monte-Carlo optimization under uncertainty based on the most significant parameters resulting from the sensitivity analysis are summarized in Table 5. Again relying on the 95\% confidence interval as performance criterion, the SSCFC_RECY configurations present the higher saving with respect to the base case with a 26.63\% reduction in the manufacturing cost. As far as the SHCF with double recycle configuration is concerned, the optimized conditions reduce the manufacturing cost with $24.62 \%$, which is a slightly lower saving compared to the base case. The optimization results for the SHCF with single recycle configuration pointed towards a reduction of the manufacturing cost by $28.35 \%$ compared with the base case.

The analysis for savings in the manufacturing cost at each stage of the process was performed using the results from Monte-Carlo optimization under uncertainty for the evaluated process configurations.

For SSCF-C_RECY 99\% of the reduction on the manufacturing cost was due to reduced enzyme loading, which can be clearly seen because instead of using $40 \mathrm{mg}$-enzyme/gcellulose, the required enzyme loadings were 27.8 and $20.2 \mathrm{mg}$-enzyme/g-cellulose for $E L_{1}$ and $E L_{2}$, respectively, meaning that $30 \%$ and $49 \%$ less enzyme addition was required. On the other hand, the required acid concentration was higher, but this is not reflected in the cost since sulphuric acid is considerably cheaper than enzymes. Moreover, when applying a higher acid concentration it is possible also to reduce the temperature of the pretreatment resulting in lower steam consumption, but technologically, the drawback is that more salt will end up in the lignin residual fraction 
affecting the combustion/gasification of this fraction negatively in the co-generation section (Pedersen \& Meyer, 2010).

As far as the SHCF with double recycle configuration is concerned, it was found that the enzyme loading had the highest impact on reducing the manufacturing cost (94\%), resulting in a reduction of the enzyme loading by more than $38 \%$ and $15 \%$ for the total amount of needed enzyme ( $E L_{1}$ and $\left.E L_{2}\right)$, respectively. These results also showed that acid loading can be further reduced by about $11 \%$, which also contributes to the total savings on the manufacturing expenses compared to the base case.

Regarding the SHCF with single recycle configuration, the reduction on the manufacturing cost was also associated with the enzyme loading where $79.3 \%$ of the difference between the base case and the optimal calculated manufacturing cost was the result of decreasing only the enzyme consumption of $E L_{1}$. On the other hand, the predicted savings on the amount of employed sulphuric acid compared with the base case was higher than $38 \%$, whereas the percentage of the cost savings compared with the expenses in the base case for the employed sulphuric acid was only $6 \%$. With regard to feedstock, it was found that the cost per gallon of produced ethanol was decreased by 7.3\% due to the increased ethanol productivity at the optimal operating conditions.

It is important to mention that the differences of the process variable conditions depend on the illustrated process configurations due to the intrinsic behaviour of each process configuration. For instance, for SHCF with double recycle the temperature of the enzymatic hydrolysis $\left(65^{\circ} \mathrm{C}\right)$ cannot be employed for SSCF- C_RECY configurations since the microorganisms carrying out the conversion of sugars into ethanol would die off as a consequence of the higher temperature conditions. 


\subsection{General Discussion}

The implementation of the systematic framework for model-based optimization of bioprocesses under uncertainty, here applied to a bioethanol case study, has shown that when following the proposed methodology in a systematic manner, it is possible: 1) to identify the significant sources of uncertainties affecting the process performance; and 2) to solve an optimization problem under uncertainty finding feasible operating conditions for bioethanol production with reduced production cost.

This structured and systematic framework also gives insight into bottlenecks in the process and thus generates ideas for prioritising experimental efforts. For example, the results from the sensitivity analysis illustrated that reducing yeast inhibition is likely to increase productivity and reduce manufacturing cost for two reasons (a) since a stream with higher ethanol concentration would be leaving the co-fermentation section and (b) increasing the tolerance of microbial growth to inhibition by ethanol would allow having higher conversion of glucose into ethanol, thereby, improving process yield in the process. Moreover, one can quantify the uncertainty in the unit production cost due to technological risks (technology under development, not proven yet). Therefore the framework helps paving the way for risk based decision making. From this point of view, the results of uncertainty and sensitivity analysis provide a quantitative basis to justify safety factors, as well as support better informed decision making thereby contributing to cost-savings in engineering projects as demonstrated elsewhere (Sin, Gernaey, Neumann, van Loosdrecht, \& Gujer, 2009).

Even though the present results are not verified by experimental works at lab or pilotscales, knowledge from molecular-protein engineering as well as process engineering was in agreement with the findings of this optimisation study. 
From the mathematical implementation point of view, while we acknowledged that the applicability of the framework requires reasonably reliable mathematical models describing different unit operations in bioprocesses, however we believe that such models are largely available in the literature (for example in the case of describing fermentation processes there is a substantial body of literature spanning from simple unstructured models to more rigour metabolic network models (Gernaey et al., 2010). And when models are not available, there are systematic methodologies available to generate models fit for the task at hand (see e.g. Sin et al., 2010). From a computational efforts point of view, it can be highlighted that when increasing the number of samples for uncertain parameters and operating variables, in general more accuracy will be found in the results. Of course, the drawback about having a large number of samples is that this will be reflected in a longer computational time, which remains feasible thanks to ongoing exponential development of computational capacity (Moore’s law). In any case, the outcome of Monte-Carlo simulations must be judged with strong basis in the knowledge of the evaluated process model under study in order to end up with feasible and reliable results (Dickman \& Gilman, 1989). Last but not least, the framework evaluated here deliberately focused on analysing the impact of uncertainties related to technical feasibility of the process (while assuming all other sources of uncertainties known) to identify the bottlenecks so as to better focus the process development efforts and resources. As the framework is generic in nature, however, it can be applied in an iterative manner to evaluate different future scenarios and to see how these affect the process development efforts. Such future scenarios may include uncertainties related to markets such as price of feedstock and product, and uncertainties related to the 
political/social environment, legislation ( $\mathrm{CO}_{2}$ footprint, climate change, etc) among others.

\section{Concluding Remarks}

This study has introduced a systematic model-based optimization framework, where the first steps involved the identification of the most critical parameters under uncertainty. Once the most significant parameters are identified and selected (reducing the complexity of the stochastic process optimization procedure), these are used to perform the stochastic optimization under parameter uncertainty, using in this case the bioethanol production from lignocellulosic biomass as a case study.

The uncertainty and sensitivity analysis identified the following most critical parameters involved in the process: For the manufacturing cost, the enzyme loading showed the strongest impact for SSCF-C_RECY and SHCF with double recycle configurations.

The results showed also that it is possible to find a better alternative operation of the plant in comparison to the base case. For instance, for the SSCF-C process configuration it was found that the manufacturing cost can be decreased by $8.7 \%$, for SSCF-C_RECY by $26.63 \%$, for SHCF with double recycle by $24.64 \%$ and for SHCF with single recycle by $28.35 \%$ compared to the base case.

Hence, based on these results one can conclude that there is an important potential reduction of the production cost of bioethanol and that the presented framework was able to identify this for the four analyzed process configurations. 


\section{Acknowledgements}

The authors kindly acknowledge the Mexican National Council for Science and Technology (CONACyT, project \# 145066) and the Danish Research Council for

Technology and Production Sciences (project \# 274-07-0339) for the financial support on the development of this project. 


\section{Nomenclature}

\begin{tabular}{|c|c|}
\hline$A_{1, X y}^{P T}$ & Pre-exponential factor for xylose production, $h^{-1}$ \\
\hline$A_{2, X y}^{P T}$ & Pre-exponential factor for xylose degradation, $h^{-1}$ \\
\hline$A_{1, A}^{P T}$ & Pre-exponential factor for arabinose production, $h^{-1}$ \\
\hline$A_{2, A}^{P T}$ & Pre-exponential factor for arabinose degradation, $h^{-1}$ \\
\hline$A_{1, G}^{P T}$ & Pre-exponential factor for glucose production, $h^{-1}$ \\
\hline$A_{2, G}^{P T}$ & Pre-exponential factor for glucose degradation, $h^{-1}$ \\
\hline$A_{1, F}^{P T}$ & Pre-exponential factor for furfural production, $h^{-1}$ \\
\hline$A_{2, F}^{P T}$ & Pre-exponential factor for furfural degradation, $h^{-1}$ \\
\hline$A_{1, A S L}^{P T}$ & Pre-exponential factor for reaction to produce ASL, $h^{-1}$ \\
\hline$A_{2, A S L}^{P T}$ & Pre-exponential factor for reaction to consume ASL, $h^{-1}$ \\
\hline$A_{3, A S L}^{P T}$ & Pre-exponential factor for reversible reaction to produce ASL, $h^{-1}$ \\
\hline$b_{i}$ & Regression coefficients in the fitted linear multivariate model \\
\hline$C_{\text {Acid }}$ & Acid concentration, $\%(w t / v)$ \\
\hline$C_{\text {An }}$ & Arabinan concentration, $g / k g$ \\
\hline$C_{\text {Ash }}$ & Ash concentration, $g / k g$ \\
\hline$C_{A S L}$ & Acid-soluble lignin concentration, $\mathrm{g} / \mathrm{kg}$ \\
\hline$C_{L n}$ & Lignin concentration, $g / k g$ \\
\hline$C_{X n}$ & Xylan concentration, $g / k g$ \\
\hline$C_{G n}$ & Glucan (cellulose) concentration, $g / k g$ \\
\hline $\mathrm{CI}$ & Confidence interval \\
\hline$C_{O C}$ & Other compounds concentration, $g / \mathrm{kg}$ \\
\hline$c^{T}$ & Constant vector of economic information, USD/kg \\
\hline$c^{T} \mathbf{x}$ & $\begin{array}{l}\text { Deterministic term of the stochastic optimization cost function, } \\
\text { USD/gal-Ethanol }\end{array}$ \\
\hline$C_{\text {yeast }}$ & Yeast concentration, g/kg \\
\hline $\begin{array}{l}\text { SHCF with double } \\
\text { recycle }\end{array}$ & $\begin{array}{l}\text { Separate hydrolysis and co-fermentation working in continuous } \\
\text { and recycle for both unit operations }\end{array}$ \\
\hline $\begin{array}{l}\text { SHCF with single } \\
\text { recycle }\end{array}$ & $\begin{array}{l}\text { Separate hydrolysis and co-fermentation working in continuous } \\
\text { and recycle for in the enzymatic hydrolysis and continuous regime } \\
\text { in the co-fermentation reactor. }\end{array}$ \\
\hline DLB1.0 & Dynamic Lignocellulosic Bioethanol model version 1.0 \\
\hline$E_{a}$ & Activation energy for enzyme $1, \mathrm{cal} / \mathrm{mol}$ \\
\hline$E_{a, \beta G}$ & Activation energy for enzyme $2, \mathrm{cal} / \mathrm{mol}$ \\
\hline
\end{tabular}




\begin{tabular}{|c|c|}
\hline$E a_{1, X y}^{P T}$ & Activation energy reaction to produce xylose, $\mathrm{J} / \mathrm{mol}$ \\
\hline$E a_{2, X y}^{P T}$ & Activation energy for xylose degradation, $\mathrm{J} / \mathrm{mol}$ \\
\hline$E a_{1, A}^{P T}$ & Activation energy reaction to produce arabinose, $\mathrm{J} / \mathrm{mol}$ \\
\hline$E a_{2, A}^{P T}$ & Activation energy reaction for arabinose degradation, $\mathrm{J} / \mathrm{mol}$ \\
\hline$E a_{1, G}^{P T}$ & Activation energy reaction to produce glucose, $\mathrm{J} / \mathrm{mol}$ \\
\hline$E a_{2, G}^{P T}$ & Activation energy reaction for glucose degradation, $\mathrm{J} / \mathrm{mol}$ \\
\hline$E a_{1, F}^{P T}$ & Activation energy reaction to produce furfural, $\mathrm{J} / \mathrm{mol}$ \\
\hline$E a_{2, F}^{P T}$ & Activation energy reaction for furfural degradation, $\mathrm{J} / \mathrm{mol}$ \\
\hline$E a_{1, A S L}^{P T}$ & Activation energy reaction to produce ASL, $\mathrm{J} / \mathrm{mol}$ \\
\hline$E a_{2, A S L}^{P T}$ & Activation energy reaction for ASL degradation, $\mathrm{J} / \mathrm{mol}$ \\
\hline$E a_{3, A S L}^{P T}$ & Activation energy for reversible reaction to produce ASL, $\mathrm{J} / \mathrm{mol}$ \\
\hline$E L_{1}$ & $\begin{array}{l}\text { Enzyme loading of exo- } \beta \text {-1,4-cellobiohydrolase + endo- } \beta \text {-1,4- } \\
\text { glucanase, } m g \text {-Enzyme/g-cellulose }\end{array}$ \\
\hline$E L_{2}$ & Enzyme loading of $\beta$-glucosidase, $m g$-Enzyme/g-cellulose \\
\hline$E_{1 \max }$ & $\begin{array}{l}\text { Maximum mass of enzyme } 1 \text { that can be adsorbed onto a unit mass } \\
\text { of substrate, } g \text {-protein } / g \text {-substrate. }\end{array}$ \\
\hline$E_{2 \max }$ & $\begin{array}{l}\text { Maximum mass of enzyme } 2 \text { that can be adsorbed onto a unit mass } \\
\text { of substrate, } g \text {-protein } / g \text {-substrate. }\end{array}$ \\
\hline$E t_{\max , G}$ & $\begin{array}{l}\text { Ethanol concentration above which cells do not grow in glucose } \\
\text { fermentation, } 95.40 \text { for } \mathrm{Et} \leq 95.4 \mathrm{~g} / \mathrm{L}, 129.90 \text { for } 95.4<E t \leq 129.9 \mathrm{~g} / \mathrm{L}\end{array}$ \\
\hline$E t_{\max , X y}$ & $\begin{array}{l}\text { Ethanol concentration above which cells do not grow in xylose } \\
\text { fermentation, } g / L \text {. }\end{array}$ \\
\hline$E t_{\max , G}^{\prime}$ & $\begin{array}{l}\text { Ethanol concentration above which cells do not produce ethanol in } \\
\text { glucose fermentation, } 103 \text { for } \mathrm{Et} \leq 103 \mathrm{~g} / \mathrm{L} \text {, } \\
136.40 \text { for } 103<E t \leq 136.4 \mathrm{~g} / \mathrm{L}\end{array}$ \\
\hline$E t_{\max , X y}^{\prime}$ & $\begin{array}{l}\text { Ethanol concentration above which cells do not produce ethanol in } \\
\text { xylose fermentation, } g / L\end{array}$ \\
\hline $\mathbf{E}_{s}\left[f\left(x, \theta_{i}\right)\right]$ & Expected value of the stochastic optimization cost function. \\
\hline$f\left(x,\left(\theta_{i}\right)\right.$ & $\begin{array}{l}\text { Uncertain term of the stochastic optimization cost function, } \\
\text { USD/gal-Ethanol }\end{array}$ \\
\hline g & Set of inequality constrains \\
\hline h & Vector of equality constrains \\
\hline$K_{\text {lad }}$ & Dissociation constant for enzyme 1, g-protein/g-substrate \\
\hline$K_{2 a d}$ & Dissociation constant for enzyme 2, g-protein/g-substrate \\
\hline$k_{1 a d, E q}$ & Rate of adsorption in equilibrium for Enzyme 1 \\
\hline$k_{2 a d, E q}$ & Rate of adsorption in equilibrium for Enzyme 2 \\
\hline
\end{tabular}




\begin{tabular}{|c|c|}
\hline$k_{1, G}^{E H}$ & $\begin{array}{l}\text { Reaction rate constant for glucose } 1 \text { in the enzymatic hydrolysis, } \\
g /(m g \cdot h)\end{array}$ \\
\hline$k_{2, G}^{E H}$ & $\begin{array}{l}\text { Reaction rate constant for glucose } 2 \text { in the enzymatic hydrolysis, } h \\
1\end{array}$ \\
\hline$k_{G 2}^{E H}$ & $\begin{array}{l}\text { Reaction rate constant for cellobiose formation in the enzymatic } \\
\text { hydrolysis, } g /(\mathrm{mg} \cdot \mathrm{h})\end{array}$ \\
\hline$K_{1 I E t}^{E H}$ & Inhibition constant for ethanol 1 in the SSCF unit, $g / k g$ \\
\hline$K_{1 I G}^{E H}$ & Inhibition constant for glucose $1, \mathrm{~g} / \mathrm{kg}$ \\
\hline$K_{2 I G}^{E H}$ & Inhibition constant for glucose $2, \mathrm{~g} / \mathrm{kg}$ \\
\hline$K_{3 I G}^{E H}$ & Inhibition constant for glucose $3, \mathrm{~g} / \mathrm{kg}$ \\
\hline$K_{11 G 2}^{E H}$ & Inhibition constant for cellobiose $1, \mathrm{~g} / \mathrm{kg}$ \\
\hline$K_{2 I G 2}^{E H}$ & Inhibition constant for cellobiose $2, \mathrm{~g} / \mathrm{kg}$ \\
\hline$K_{1 I X y}^{E H}$ & Inhibition constant for xylose $1, g / k g$ \\
\hline$K_{2 I X y}^{E H}$ & Inhibition constant for xylose $2, \mathrm{~g} / \mathrm{kg}$ \\
\hline$K_{3 I X y}^{E H}$ & Inhibition constant for xylose $3, \mathrm{~g} / \mathrm{kg}$ \\
\hline$K_{1 G}^{C F}$ & Monod constant, for growth on glucose, $g / L$ \\
\hline$K_{2 X y}^{C F}$ & Monod constant, for growth on xylose, $g / L$ \\
\hline$K_{5 I G}^{\prime C F}$ & Inhibition constant, for product formation from glucose, $g / L$ \\
\hline$K_{6 I X y}^{\prime C F}$ & Inhibition constant, for product formation from xylose, $g / L$ \\
\hline$K_{5 G}^{\prime C F}$ & Monod constant, for product formation from glucose, $g / L$ \\
\hline$K_{6 X Y}^{\prime C F}$ & Monod constant, for product formation from xylose, $g / L$ \\
\hline$K_{1 X_{G} I G}^{C F}$ & Inhibition constant, for growth on glucose, $g / L$ \\
\hline$K_{2 X_{X y} I X y}^{C F}$ & Inhibition constant, for growth on xylose, $g / L$ \\
\hline$K_{M}$ & Substrate (cellobiose) saturation constant, $g / \mathrm{kg}$ \\
\hline KPI & Key performance indices \\
\hline LHS & Latin Hypercube Sampling \\
\hline$m_{G}$ & Maintenance coefficient in glucose fermentation, $h^{-1}$ \\
\hline$m_{X y}$ & Maintenance coefficient in xylose fermentation, $h^{-1}$ \\
\hline$n_{A}^{P T}$ & Order of reaction to produce arabinose \\
\hline$n_{A S L}^{P T}$ & Order of reaction to produce ASL \\
\hline$n_{F}^{P T}$ & Order of reaction to produce furfural \\
\hline$n_{G}^{P T}$ & Order of reaction to produce glucose \\
\hline$n_{X y}^{P T}$ & Order of reaction to produce xylose \\
\hline
\end{tabular}




\begin{tabular}{|c|c|}
\hline$N P$ & Total number of uncertain parameters \\
\hline$P_{C, D k}$ & Pressure in the condenser of distillation column $k=1,2, \mathrm{~atm}$ \\
\hline$P_{R, D k}$ & Pressure in the reboiler of distillation column $k=1,2, a t m$ \\
\hline PSE & Process System Engineering \\
\hline $\mathrm{R}^{2}$ & Model determination coefficient \\
\hline$R$ & Universal gas constant, $1.9872 \mathrm{cal} / \mathrm{mol} \cdot \mathrm{K}$ \\
\hline SAA & Sample average approximation method \\
\hline SSCF-C & $\begin{array}{l}\text { Simultaneous Saccharification and Co-Fermentation operating in } \\
\text { continuous regime. }\end{array}$ \\
\hline SSCF-C_RECY & $\begin{array}{l}\text { Simultaneous Saccharification and Co-Fermentation operating in } \\
\text { continuous and recycle of unreacted solids. }\end{array}$ \\
\hline SRC & Standardized regression coefficient \\
\hline$T_{E H}$ & Enzymatic hydrolysis reactor temperature, ${ }^{\circ} \mathrm{C}$ \\
\hline$T_{P T}$ & pretreatment reactor temperature, ${ }^{\circ} \mathrm{C}$ \\
\hline$T_{S S C F}$ & SSCF reactor temperature, ${ }^{\circ} \mathrm{C}$ \\
\hline USD & United state Dollar \\
\hline $\mathbf{x}$ & Vector of design variables to optimize \\
\hline$Y_{E t_{G} / G}$ & Product yield constant (g-ethanol/g-glucose), g/g \\
\hline$Y_{E t_{x y} / X y}$ & Product yield constant (g-ethanol/g-xylose), g/g \\
\hline$y_{\text {reg }}$ & $\begin{array}{l}\text { Linear multivariate model fit of the Monte-Carlo simulation } \\
\text { outputs }\end{array}$ \\
\hline$Y_{X_{G} / G}$ & Cell yield constant from glucose (g-cells/g-substrate), $g / g$ \\
\hline$Y_{X_{X \prime} / X y}$ & Cell yield constant from xylose ( $g$-cells/g-substrate), $g / g$ \\
\hline$Z$ & Objective function, USD/gal Ethanol \\
\hline \multicolumn{2}{|c|}{ Subscript and superscript } \\
\hline ADD & Additives \\
\hline$C F$ & Co-fermentation \\
\hline$E H$ & Enzymatic hydrolysis \\
\hline Et & Ethanol \\
\hline FS & Feedstock \\
\hline$i$ & Parameters \\
\hline$j$ & Operating conditions sample \\
\hline$k$ & Distillation column index, $k=1,2$. \\
\hline$L B$ & Lower bound \\
\hline$P T$ & Pretreatment section \\
\hline$U B$ & Upper bound \\
\hline UT & Utilities \\
\hline
\end{tabular}




\begin{tabular}{|l|l|}
\hline & \\
\hline Greek letters & Constant relating substrate reactivity with degree of hydrolysis \\
\hline$\alpha$ & $\begin{array}{l}\text { Constants in product inhibition model in glucose fermentation } \\
1.29 \text { for Et } \leq 95.4 \mathrm{~g} / \mathrm{L}, 0.25 \text { for } 95.4<E t \leq 129.9 \mathrm{~g} / \mathrm{L}\end{array}$ \\
\hline$\beta_{G}$ & Global sensitivity measure of parameter $i$ \\
\hline$\beta_{i}$ & $\begin{array}{l}\text { Constant in the product inhibition model in xylose fermentation, } \\
\text { g/L }\end{array}$ \\
\hline$\beta_{X y}$ & Maximum specific rate of glucose formation \\
\hline$\gamma^{G}$ & Maximum specific rate of xylose formation, $g / L$ \\
\hline$\gamma^{X y}$ & Mean value of manufacturing cost \\
\hline$\mu$ & Maximum specific growth rate in glucose fermentation, $h^{-1}$ \\
\hline$\mu_{\max , G}$ & Maximum specific growth rate in xylose fermentation, $h^{-1}$ \\
\hline$\mu_{\max , X y}$ & Maximum specific rate of glucose formation, $h^{-1}$ \\
\hline$v_{\max , G}$ & Maximum specific rate of xylose formation, $h^{-1}$ \\
\hline$v_{\max , X y}$ & Values of uncertain parameters $i$ \\
\hline$\theta_{i}$ & Lower bound of uncertain parameters $i$ \\
\hline$\theta_{i}^{L B}$ & Upper bound of uncertain parameters $i$ \\
\hline$\theta_{i}^{U B}$ & Standard deviation for manufacturing cost \\
\hline$\sigma$ & Standard deviation of uncertain parameters \\
\hline$\sigma_{\theta_{i}}$ & Standard deviation of model output of the Monte-Carlo \\
\hline$\sigma_{y}$ & Rariance of manufacturing cost fed insoluble solid to liquid in the pretreatment \\
\hline$\sigma^{2}$ & \\
\hline$\phi$ &
\end{tabular}




\section{Appendix}

Table A.1. Expert review of input uncertainty of parameters for the bioethanol production process model

\begin{tabular}{|c|c|c|c|c|c|c|c|}
\hline ID & Parameter & Units & $\begin{array}{l}\text { Default } \\
\text { Value }\end{array}$ & $\begin{array}{l}\text { Lower } \\
\text { bound }\end{array}$ & $\begin{array}{l}\text { Upper } \\
\text { bound }\end{array}$ & $\begin{array}{c}\text { Uncertainty } \\
\text { class }\end{array}$ & $\begin{array}{l}\text { Section of } \\
\text { the process }\end{array}$ \\
\hline 1 & $C_{G n}$ & $g / k g$ & 112.20 & 84.15 & 140.25 & 2 & FS \\
\hline 2 & $C_{X n}$ & $g / k g$ & 63.30 & 47.48 & 79.13 & 2 & FS \\
\hline 3 & $C_{A n}$ & $g / \mathrm{kg}$ & 8.70 & 6.53 & 10.88 & 2 & FS \\
\hline 4 & $C_{L n}$ & $g / k g$ & 54.00 & 40.50 & 67.50 & 2 & FS \\
\hline 5 & $C_{\text {Ash }}$ & $g / k g$ & 15.60 & 11.70 & 19.50 & 2 & FS \\
\hline 6 & $C_{O C}$ & $g / k g$ & 46.20 & 34.65 & 57.75 & 2 & FS \\
\hline 7 & $A_{1, X y}^{P T}$ & $h^{-1}$ & $1.09 \cdot 10^{14}$ & $1.04 \cdot 10^{14}$ & $1.15 \cdot 10^{14}$ & 1 & PT \\
\hline 8 & $E a_{1, X y}^{P T}$ & $\mathrm{~J} / \mathrm{mol}$ & 105900 & 100605 & 111195 & 1 & PT \\
\hline 9 & $n_{X y}^{P T}$ & - & 0.97 & 0.92 & 1.02 & 1 & PT \\
\hline 10 & $A_{2, X y}^{P T}$ & $h^{-1}$ & $9.58 \cdot 10^{15}$ & $9.10 \cdot 10^{15}$ & $1.01 \cdot 10^{16}$ & 1 & PT \\
\hline 11 & $E a_{2, X y}^{P T}$ & $\mathrm{~J} / \mathrm{mol}$ & $1.18 \cdot 10^{5}$ & $1.12 \cdot 10^{5}$ & $1.23 \cdot 10^{5}$ & 1 & PT \\
\hline 12 & $A_{1, A}^{P T}$ & $h^{-1}$ & $5.40 \cdot 10^{11}$ & $5.13 \cdot 10^{11}$ & $5.67 \cdot 10^{11}$ & 1 & PT \\
\hline 13 & $E a_{1, A}^{P T}$ & $\mathrm{~J} / \mathrm{mol}$ & $9.03 \cdot 10^{4}$ & $8.58 \cdot 10^{4}$ & $9.48 \cdot 10^{4}$ & 1 & PT \\
\hline 14 & $A_{2, A}^{P T}$ & $h^{-1}$ & $7.63 \cdot 10^{10}$ & $7.25 \cdot 10^{10}$ & $8.01 \cdot 10^{10}$ & 1 & PT \\
\hline 15 & $E a_{2, A}^{P T}$ & $\mathrm{~J} / \mathrm{mol}$ & $7.92 \cdot 10^{4}$ & $7.52 \cdot 10^{4}$ & $8.32 \cdot 10^{4}$ & 1 & PT \\
\hline 16 & $n_{A}^{P T}$ & - & 0.82 & 0.78 & 0.86 & 1 & PT \\
\hline 17 & $A_{1, G}^{P T}$ & $h^{-1}$ & $2.88 \cdot 10^{13}$ & $2.74 \cdot 10^{13}$ & $3.02 \cdot 10^{13}$ & 1 & PT \\
\hline 18 & $E a_{1, G}^{P T}$ & $\mathrm{~J} / \mathrm{mol}$ & $1.07 \cdot 10^{5}$ & $1.02 \cdot 10^{5}$ & $1.13 \cdot 10^{5}$ & 1 & PT \\
\hline 19 & $A_{2, G}^{P T}$ & $h^{-1}$ & $9.58 \cdot 10^{15}$ & $9.10 \cdot 10^{15}$ & $1.01 \cdot 10^{16}$ & 1 & PT \\
\hline 20 & $E a_{2, G}^{P T}$ & $\mathrm{~J} / \mathrm{mol}$ & $1.29 \cdot 10^{5}$ & $1.22 \cdot 10^{5}$ & $1.35 \cdot 10^{5}$ & 1 & PT \\
\hline 21 & $n_{G}^{P T}$ & - & 0.77 & 0.74 & 0.81 & 1 & PT \\
\hline 22 & $A_{1, F}^{P T}$ & $h^{-1}$ & $1.17 \cdot 10^{17}$ & $1.11 \cdot 10^{17}$ & $1.23 \cdot 10^{17}$ & 1 & PT \\
\hline 23 & $E a_{1, F}^{P T}$ & $\mathrm{~J} / \mathrm{mol}$ & $1.46 \cdot 10^{5}$ & $1.38 \cdot 10^{5}$ & $1.53 \cdot 10^{5}$ & 1 & PT \\
\hline 24 & $A_{2, F}^{P T}$ & $h^{-1}$ & $6.66 \cdot 10^{11}$ & $6.33 \cdot 10^{11}$ & $6.99 \cdot 10^{11}$ & 1 & PT \\
\hline 25 & $E a_{2, F}^{P T}$ & $\mathrm{~J} / \mathrm{mol}$ & $8.57 \cdot 10^{4}$ & $8.14 \cdot 10^{4}$ & $9.00 \cdot 10^{4}$ & 1 & PT \\
\hline 26 & $n_{F}^{P T}$ & - & 0.84 & 0.80 & 0.88 & 1 & PT \\
\hline
\end{tabular}




\begin{tabular}{|c|c|c|c|c|c|c|c|}
\hline 27 & $A_{1, A S L}^{P T}$ & $h^{-1}$ & $4.16 \cdot 10^{8}$ & $3.95 \cdot 10^{8}$ & $4.37 \cdot 10^{8}$ & 1 & PT \\
\hline 28 & $E a_{1, A S L}^{P T}$ & $\mathrm{~J} / \mathrm{mol}$ & $7.72 \cdot 10^{4}$ & $7.33 \cdot 10^{4}$ & $8.11 \cdot 10^{4}$ & 1 & PT \\
\hline 29 & $A_{2, A S L}^{P T}$ & $h^{-1}$ & $2.07 \cdot 10^{3}$ & $1.96 \cdot 10^{3}$ & $2.17 \cdot 10^{3}$ & 1 & PT \\
\hline 30 & $E a_{2, A S L}^{P T}$ & $\mathrm{~J} / \mathrm{mol}$ & $2.06 \cdot 10^{4}$ & $1.95 \cdot 10^{4}$ & $2.16 \cdot 10^{4}$ & 1 & PT \\
\hline 31 & $A_{3, A S L}^{P T}$ & $h^{-1}$ & $8.68 \cdot 10^{8}$ & $8.24 \cdot 10^{8}$ & $9.11 \cdot 10^{8}$ & 1 & PT \\
\hline 32 & $E a_{3, A S L}^{P T}$ & $\mathrm{~J} / \mathrm{mol}$ & $7.34 \cdot 10^{4}$ & $6.97 \cdot 10^{4}$ & $7.71 \cdot 10^{4}$ & 1 & PT \\
\hline 33 & $n_{A S L}^{P T}$ & - & 0.84 & 0.80 & 0.89 & 1 & PT \\
\hline 34 & $K_{\text {lad }}$ & $\begin{array}{l}\text { g-protein } / g \text { - } \\
\text { substrate }\end{array}$ & 0.40 & 0.30 & 0.50 & 2 & EH \\
\hline 35 & $K_{\text {2ad }}$ & $\begin{array}{l}\text { g-protein } / g \text { - } \\
\text { substrate }\end{array}$ & 0.10 & 0.08 & 0.13 & 2 & EH \\
\hline 36 & $E_{1 \max }$ & $\begin{array}{l}\text { g-protein/g- } \\
\text { substrate }\end{array}$ & 0.06 & 0.05 & 0.08 & 2 & EH \\
\hline 37 & $E_{2 \max }$ & $\begin{array}{l}\text { g-protein } / g- \\
\text { substrate }\end{array}$ & 0.01 & 0.01 & 0.01 & 2 & EH \\
\hline 38 & $E_{a}$ & $\mathrm{cal} / \mathrm{mol}$ & -5540 & -6925 & -4155 & 2 & EH \\
\hline 39 & $\alpha$ & - & 1.00 & 0.75 & 1.25 & 2 & $\mathrm{EH}$ \\
\hline 40 & $k_{G 2}^{E H}$ & $g /(m g \cdot h)$ & 22.30 & 16.73 & 27.88 & 2 & EH \\
\hline 41 & $K_{1 I G 2}^{E H}$ & $g / \mathrm{kg}$ & 0.02 & 0.01 & 0.02 & 2 & EH \\
\hline 42 & $K_{1 I G}^{E H}$ & $g / k g$ & 0.10 & 0.08 & 0.13 & 2 & EH \\
\hline 43 & $K_{1 I X y}^{E H}$ & $g / k g$ & 0.10 & 0.08 & 0.13 & 2 & $\mathrm{EH}$ \\
\hline 44 & $k_{1, G}^{E H}$ & $\mathrm{~kg} /(\mathrm{g} \cdot \mathrm{h})$ & 7.18 & 5.39 & 8.98 & 2 & EH \\
\hline 45 & $K_{2 I G 2}^{E H}$ & $g / k g$ & 132 & 99 & 165 & 2 & EH \\
\hline 46 & $K_{2 I G}^{E H}$ & $g / k g$ & 0.04 & 0.03 & 0.05 & 2 & $\mathrm{EH}$ \\
\hline 47 & $K_{2 I X y}^{E H}$ & $g / k g$ & 0.20 & 0.15 & 0.25 & 2 & $\mathrm{EH}$ \\
\hline 48 & $k_{2, G}^{E H}$ & $h^{-1}$ & 285.50 & 214.13 & 356.88 & 2 & EH \\
\hline 49 & $K_{M}$ & $g / k g$ & 24.30 & 18.23 & 30.38 & 2 & EH \\
\hline 50 & $K_{3 I G}^{E H}$ & $g / k g$ & 3.90 & 2.93 & 4.88 & 2 & $\mathrm{EH}$ \\
\hline 51 & $K_{3 I X y}^{E H}$ & $g / k g$ & 201.00 & 150.75 & 251.25 & 2 & $\mathrm{EH}$ \\
\hline 52 & $k_{1 a d, E q}$ & $h^{-1}$ & $1.00 \cdot 10^{5}$ & $7.50 \cdot 10^{4}$ & $1.25 \cdot 10^{5}$ & 2 & $\mathrm{EH}$ \\
\hline 53 & $k_{2 a d, E q}$ & $h^{-1}$ & $1.00 \cdot 10^{5}$ & $7.50 \cdot 10^{4}$ & $1.25 \cdot 10^{5}$ & 2 & EH \\
\hline 54 & $E_{a, \beta G}$ & $\mathrm{cal} / \mathrm{mol}$ & -10235.12 & -12793.9 & -7676.34 & 2 & EH \\
\hline 55 & $\mu_{\max , G}$ & $h^{-1}$ & 0.66 & 0.63 & 0.70 & 1 & $\mathrm{CF}$ \\
\hline 56 & $v_{\max , G}$ & $h^{-1}$ & 2.01 & 1.90 & 2.11 & 1 & $\mathrm{CF}$ \\
\hline 57 & $K_{5 G}^{\prime C F}$ & $g / L$ & 1.34 & 1.27 & 1.41 & 1 & $\mathrm{CF}$ \\
\hline
\end{tabular}




\begin{tabular}{|c|c|c|c|c|c|c|c|}
\hline 58 & $K_{1 G}^{C F}$ & $g / L$ & 0.57 & 0.54 & 0.59 & 1 & CF \\
\hline 59 & $K_{1 X_{G} I G}^{C F}$ & $g / L$ & 283.7 & 269.5 & 297.9 & 1 & CF \\
\hline 60 & $K_{5 I G}^{{ }^{C F}}$ & $g / L$ & 4890 & 4645.5 & 5134.5 & 1 & CF \\
\hline 61 & $E t_{\text {max }, G}$ & $g / L$ & 95.40 & 90.63 & 100.17 & 1 & CF \\
\hline 62 & $E t_{\text {max }, G}^{\prime}$ & $g / L$ & 103.03 & 97.88 & 108.18 & 1 & CF \\
\hline 63 & $\beta_{G}$ & - & 1.290 & 1.226 & 1.355 & 1 & CF \\
\hline 64 & $\gamma^{G}$ & - & 1.420 & 1.349 & 1.491 & 1 & CF \\
\hline 65 & $m_{G}$ & $h^{-1}$ & 0.097 & 0.092 & 0.102 & 1 & CF \\
\hline 66 & $Y_{E t_{G} / G}$ & $\begin{array}{l}\text { g-product/g- } \\
\text { substrate }\end{array}$ & 0.47 & 0.45 & 0.49 & 1 & CF \\
\hline 67 & $Y_{X_{G} / G}$ & $\begin{array}{l}\text { g-product/g- } \\
\text { substrate }\end{array}$ & 0.12 & 0.11 & 0.12 & 1 & CF \\
\hline 68 & $\mu_{\mathrm{max}, X y}$ & $h^{-1}$ & 0.19 & 0.18 & 0.20 & 1 & CF \\
\hline 69 & $v_{\max , X y}$ & $h^{-1}$ & 0.25 & 0.24 & 0.26 & 1 & CF \\
\hline 70 & $K_{6 X y}^{{ }^{C F}}$ & $g / L$ & 3.40 & 3.23 & 3.57 & 1 & CF \\
\hline 71 & $K_{2 X y}^{C F}$ & $g / L$ & 3.40 & 3.23 & 3.57 & 1 & CF \\
\hline 72 & $K_{2 X_{X y} X X y}^{C F}$ & $g / L$ & 18.10 & 17.20 & 19.01 & 1 & CF \\
\hline 73 & $K_{6 I X y}^{\prime C F}$ & $g / L$ & 81.30 & 77.24 & 85.37 & 1 & CF \\
\hline 74 & $E t_{\max , X y}$ & $g / L$ & 59.04 & 56.09 & 61.99 & 1 & $\mathrm{CF}$ \\
\hline 75 & $E t_{\text {max }, X y}^{\prime}$ & $g / L$ & 60.20 & 57.19 & 63.21 & 1 & CF \\
\hline 76 & $\beta_{X y}$ & - & 1.04 & 0.98 & 1.09 & 1 & CF \\
\hline 77 & $\gamma^{X y}$ & - & 0.61 & 0.58 & 0.64 & 1 & $\mathrm{CF}$ \\
\hline 78 & $m_{X y}$ & $h^{-1}$ & 0.07 & 0.06 & 0.07 & 1 & $\mathrm{CF}$ \\
\hline 79 & $Y_{E t_{x y} / X y}$ & $\begin{array}{l}\text { g-product/g- } \\
\text { substrate }\end{array}$ & 0.40 & 0.38 & 0.42 & 1 & CF \\
\hline 80 & $Y_{X_{X y} / X y}$ & $\begin{array}{l}\text { g-product/g- } \\
\text { substrate }\end{array}$ & 0.16 & 0.15 & 0.17 & 1 & CF \\
\hline
\end{tabular}

The uncertainty class 1 and 2 correspond to $5 \%$ and $25 \%$ of variability of the default values, respectively. FS: Feedstock, PT: Pretreatment (Lavarack, Griffin, \& Rodman, 2002)); EH: Enzymatic hydrolysis (Kadam, Rydholm, \& McMillan, 2004); CF: Cofermentation (Krishnan, Ho, \& Tsao, 1999). 
Table A.2. Pretreatment mathematical model (Lavarack et al. 2002).

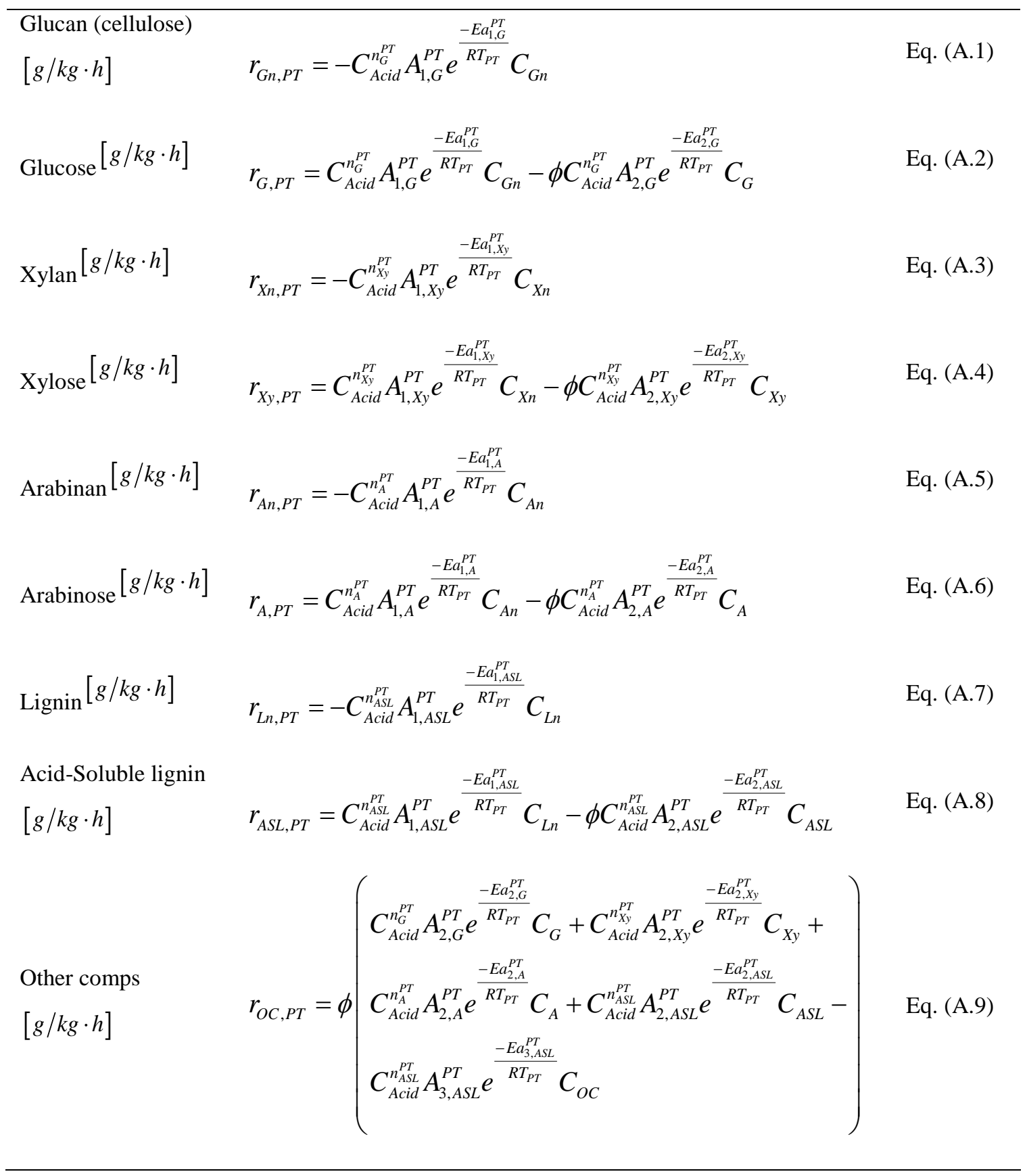


Table A.3. Kinetic expressions of the enzymatic hydrolysis model (Kadam et al., 2004).

\begin{tabular}{|c|c|c|}
\hline $\begin{array}{l}\text { Cellulose to cellobiose, } \\
{[\mathrm{g} / \mathrm{kg} \cdot \mathrm{h}]}\end{array}$ & $r_{1, E H}=\frac{k_{G 2}^{E H} C_{E_{1 B}} R_{G n} C_{G n}}{1+\frac{C_{G_{2}}}{K_{1 I G 2}^{E H}}+\frac{C_{G}}{K_{1 I G}^{E H}}+\frac{C_{X y}}{K_{1 I X y}^{E H}}}$ & Eq. (A.10) \\
\hline $\begin{array}{l}\text { Cellulose to glucose, } \\
{[\mathrm{g} / \mathrm{kg} \cdot \mathrm{h}]}\end{array}$ & $r_{2, E H}=\frac{k_{1, G}^{E H}\left(C_{E_{1 B}}+C_{E_{2 B}}\right) R_{G n} C_{G n}}{1+\frac{C_{G_{2}}}{K_{2 I G 2}^{E H}}+\frac{C_{G}}{K_{2 I G}^{E H}}+\frac{C_{X y}}{K_{2 I X y}^{E H}}}$ & Eq. (A.11) \\
\hline $\begin{array}{l}\text { Cellobiose to glucose, } \\
{[\mathrm{g} / \mathrm{kg} \cdot \mathrm{h}]}\end{array}$ & $r_{3, E H}=\frac{k_{2, G}^{E H} C_{E_{2 F}} C_{G_{2}}}{K_{M}\left(1+\frac{C_{G}}{K_{3 I G}^{E H}}+\frac{C_{X y}}{K_{3 I X y}^{E H}}\right)+C_{G_{2}}}$ & Eq. (A.12) \\
\hline $\begin{array}{l}\text { Enzyme Adsorption, } \\
{[\mathrm{g} / \mathrm{kg} \cdot \mathrm{h}]}\end{array}$ & $C_{E_{i \mathrm{~B}}}=\frac{E_{i \max } K_{i \mathrm{ad}} C_{E_{\mathrm{Fi}}} C_{G n}}{1+K_{i \mathrm{iad}} C_{E_{\mathrm{iF}}}}$ & Eq. (A.13) \\
\hline Enzyme, $[g / k g]$ & $C_{E_{T i}}=C_{E_{F i}}+C_{E_{B i}}$ & Eq. (A.14) \\
\hline Substrate reactivity & $R_{G n}=\alpha C_{G n} / C_{G n}^{0}$ & Eq. (A.15) \\
\hline Temp. dependence & $k_{i r(T 2)}=k_{i r(T 1)} e^{-E_{a i} / R(1 / T 1-1 / T 2)}, 30^{\circ} \mathrm{C} \leq T \leq 55^{\circ} \mathrm{C}$ & Eq. (A.16) \\
\hline $\begin{array}{l}\text { Cellulose kinetic, } \\
{[\mathrm{g} / \mathrm{kg} \cdot \mathrm{h}]}\end{array}$ & $r_{G n, E H}=-r_{1, E H}-r_{2, E H}$ & Eq. (A.17) \\
\hline $\begin{array}{l}\text { Cellobiose kinetic, } \\
{[\mathrm{g} / \mathrm{kg} \cdot \mathrm{h}]}\end{array}$ & $r_{G_{2}, E H}=1.056 r_{1, E H}-r_{3, E H}$ & Eq. (A.18) \\
\hline $\begin{array}{l}\text { Glucose kinetic, } \\
{[\mathrm{g} / \mathrm{kg} \cdot \mathrm{h}]}\end{array}$ & $r_{G, E H}=1.111 r_{2, E H}+1.053 r_{3, E H}$ & Eq. (A.19) \\
\hline Water kinetic, $[g / k g \cdot h]$ & $r_{W, E H}=-0.055 r_{1, E H}-0.111 r_{2, E H}-1.05263 r_{3, E H}$ & Eq. (A.20) \\
\hline
\end{tabular}


Table A.4. Kinetic expressions of the co-fermentation model (Krishnan et al., 1999).

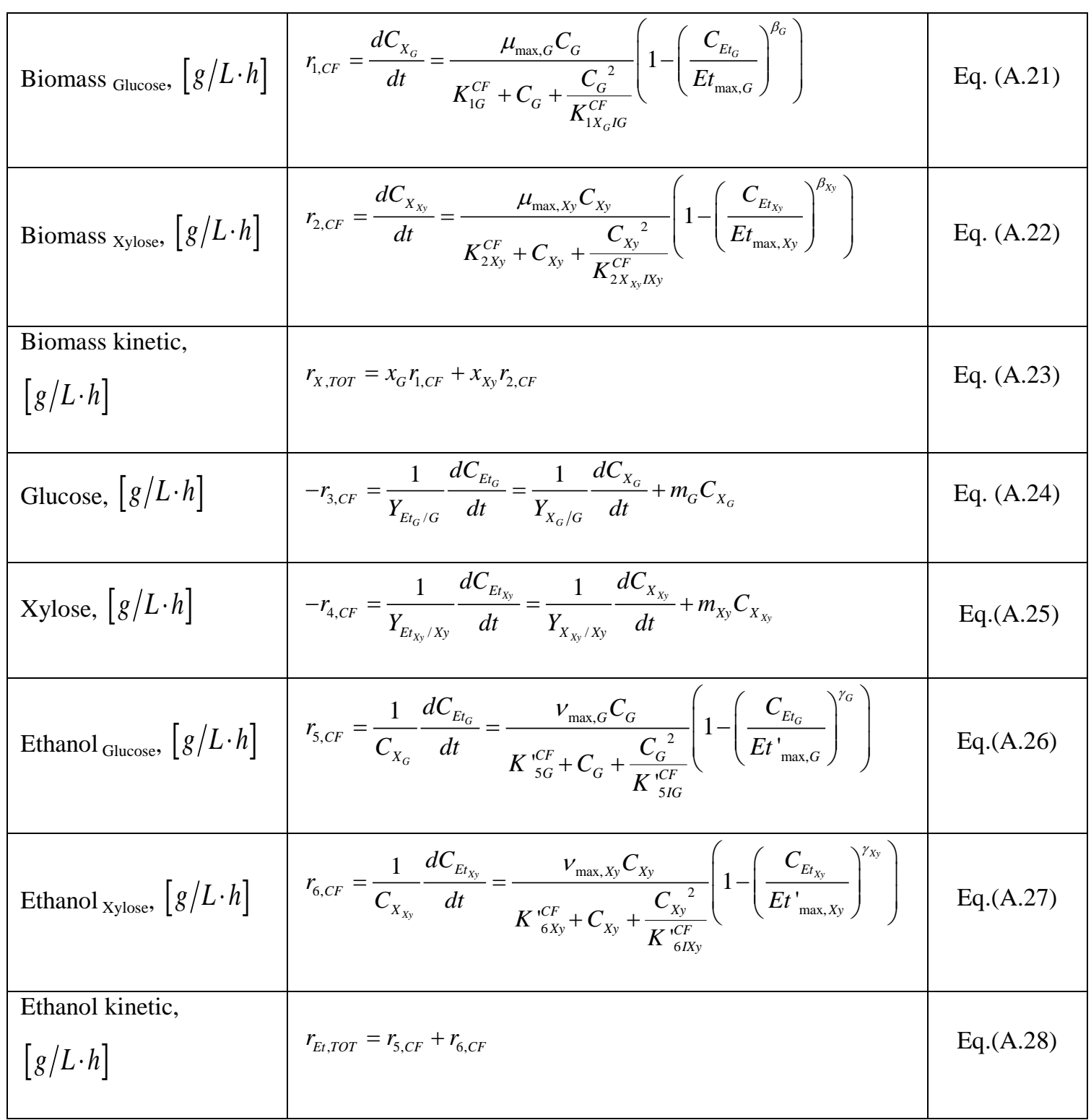




\section{References}

Acevedo, J., \& Pistikopoulos, E. N. (1996). A Parametric MINLP Algorithm for Process Synthesis Problems under Uncertainty. Industrial and Engineering Chemistry Reserach , 35, 147-158.

Aden, A., Ruth, M., Ibsen, K., Jechura, J., Neeves, K., Sheehan, J., et al. (2002).

Lignocellulosic Biomass to Ethanol Process Design and Economics Utilizing Co-

Current Dilute Acid Prehydrolysis and Enzymatic Hydrolysis for Corn Stover. Golden, CO: National Renewable Energy Laboratory.

Al-Qahtani, K., \& Elkamel, A. (2010). Robust planning of multisite refinery networks: Optimization under uncertainty. Computers and Chemical Engineering , 34, 985-995. Alvarado-Morales, M., Terra, J., Gernaey, K. V., Woodley, J. M., \& Gani, R. (2009). Biorefining: Computer Aided Tool for Sustainable Design and Analysis of Bioethanol Production. Chemical Engineering Research and Design , 87, 1171-1183.

Bao, B., Ng, D. K., Tay, D. H., Jiménez-Gutiérrez, A., \& El-Halwagi, M. M. (2011). A shortcut method for the preliminary synthesis of process-technology pathways: An optimization approach and application for the conceptual design of integrated biorefineries. Computers and Chemical Engineering , 35, 1374- 1383.

Dickman, B. H., \& Gilman, M. J. (1989). Monte Carlo Optimization. Journal of Optimization Theory And Applications , 60 (1), 149-157.

Gallagher, K., \& Sambridge, M. (1994). Genetic Algorithms: A Powerful Tool for Large-Scale Nonlinear Optimization Problems. Computers \& Geosciences , 20 (7/8), 1229-1236. 
Gernaey, K. V., Lantz, A. E., Tufvesson, P., Woodley, J. M., \& Sin, G. (2010). Application of Mechanistic Models to Fermentation and Biocatalysis for NextGeneration Processes. Trends in Biotechnology , 28, 346-354.

Grossmann, I. E., \& Guillén-Gonsálbez, G. (2010). Scope for the Application of Mathematical Programming Techniques in the Syntesis and Planning of Sustainable Processes. Computers and Chemical Engineering , 34, 1365-1376.

Hansen, K. R., Grunow, M., \& Gani, R. (2011). Robust Market Launch Planning for a Multi-Echelon Pharmaceutical Supply Chain. Computer Aided Chemical Engineering , 29A, 935-939.

Helton, J. C., \& Davis, F. (2003). Latin hypercube sampling and the propagation of uncertainty in analyses of complex systems. Reliability Engineering \& System Safety , 81, 23-69.

Humbird, D., Davis, R., Tao, L., Kichin, C., Hsu, D., Aden, A., et al. (2011). Process Design and Economics for Biochemical Conversion of Lignocellulosic Biomass to Ethanol. Golden, CO: National Renewable Energy Laboratory.

Iman, R. L., \& Conover, W. J. (1982). A Distribution-Free Approach to Inducing Rank Correlation among Input Variables. Communication in Statistics - Simulation and Computation , 11 (3), 311-334.

Kadam, K., Rydholm, E., \& McMillan, J. (2004). Development and validation of a kinetic model for enzymatic saccharification of lignocellulosic biomass. Biotechnology Progress , 20, 698-705. 
Karuppiah, R., Martín, M., \& Grossmann, I. E. (2010). A simple heuristic for reducing the number of scenarios in two-stage stochastic programming. Computers and Chemical Engineering , 34, 1246-1255.

Karuppiah, R., Peschel, A., Grossmann, I. E., Martín, M., Martinson, W., \& Zullo, L. (2008). Energy Optimization for the Design of Corn-Based Ethanol Plants. AIChE Journal , 54 (6), 1499-1525.

Kasaš, M., Kravajna, Z., \& Pintarič, Z. N. (2011). Design of Flexible Process Flow Sheets with Large Number of Uncetain Parameters. Computer-Aided Chemical Engineering , 29A, 407-411.

Kleywegt, A. J., Shapiro, A., \& Homem-de-Mello, T. (2001). The Sample Average Approximation Method for Stochastic Discrete Optimization. Society of Industrial and Applied Mathematics , 12 (2), 479-502.

Krishnan, M. S., Ho, N. W., \& Tsao, G. T. (1999). Fermentation kinetics of ethanol production from glucose and xylose by recombinant Saccharomyces 1400(pLNH33). Applied Biochemistry and Biotechnology , 77-79, 373-388.

Lavarack, B. P., Griffin, G. J., \& Rodman, D. (2002). The acid hydrolysis of sugarcane bagasse hemicellulose to produce xylose, arabinose, glucose and other products. Biomass and Bioenergy , 23, 367-380.

Martín, M., Ahmetovič, E., \& Grossmann, I. E. (2011). Optimization of Water Consumption in Second Generation Bioethanol Plants. Industrial \& Engineering Chemistry Research , 50 (7), 3705-3721. 
Morales-Rodriguez, R., Gernaey, K. V., Meyer, A. S., \& Sin, G. (2011). A

Mathematical Model for Simultaneous Saccharification and Co-Fermentation of C6 and C5 Sugars. Chinese Journal of Chemical Engineering , 19 (2), 185-191.

Morales-Rodriguez, R., Meyer, A. S., Gernaey, K. V., \& Sin, G. (2011a). A framework for model-based optimization of bioprocesses under uncertainty: Identifying critical parameters and operating variables. Computer Aided Chemical Engineering , 29A, 1456-1459.

Morales-Rodriguez, R., Meyer, A. S., Gernaey, K. V., \& Sin, G. (2011b). Dynamic model-based evaluation of process configurations for integrated operation of hydrolysis and co-fermentation for bioethanol production from lignocellulose. Bioresource Technology , 102, 1174-1184.

Pedersen, M., \& Meyer, A. S. (2010). Lignocellulose Pretreatment - Understanding Biomatrix Opening in Relation to Temperature and $\mathrm{pH}$ during Pretreatment. New Biotechnology , 27 (6), 739-750.

Pintarič, Z. N., \& Kravanja, Z. (2008). Identification of critical points for the design and synthesis of flexible processes. Computers and Chemical Engineering , 32, 1603-1624.

Ricardez-Sandoval, L. A., Douglas, P. L., \& Budman, H. B. (2011). A methodology for the simultaneous design and control of large-scale systems under process parameter uncertainty. Computers and Chemical Engineering , 35, 307-318.

Seader, J. D., \& Henley, E. J. (2006). Separation Process Principles. Hoboken, NJ, USA: John Wiley \& Sons. 
Shapiro, A., Dentcheva, D., \& Ruszczyński, A. (2009). Lectures on Stochastic Programming - Modelling and Theory. Philadelphia, PA, USA: Society for Industrial and Applied Mathematics and the Mathematical Programming Society.

Sin, G., Gernaey, K. V., \& Lantz, A. E. (2009). Good Modeling Practice for PAT Applications: Propagation of Input Uncertainty and Sensitivity Analysis. Biotechnology Progress , 25 (4), 1043-1053.

Sin, G., Gernaey, K. V., Neumann, M. B., van Loosdrecht, M. C., \& Gujer, W. (2009). Uncertainty analysis in WWTP model applications: A critical discussion using an example from design. Water Research , 43, 2894-2906.

Sin, G., Meyer, A. S., \& Gernaey, K. V. (2010). Assessing reliability of cellulose hydrolysis models to support bioefuel process design-identifiability and uncertainty analysis. Computers and Chemical Engineering , 34, 1385-1392.

Smith, J. M., Van Ness, H. C., \& Abbott, M. M. (2001). Introduction to Chemical Engineering Thermodynamics (6th ed.). New York, NY, USA: McGraw-Hill.

Verderame, P. V., \& Floudas, C. A. (2011). Multisite Planning under Demand and Transportation Time Uncertainty: Robust Optimization and Conditional Value-at-Risk Frameworks. Industrial \& Engineering Chemistry Research , 50 (9), 4959-4982. Wang, J., \& Rong, G. (2010). Robust Optimization Model for Crude Oil Scheduling under Uncertainty. Industrial \& Engineering Chemistry Research , 49, 1737-1748. You, F., \& Grossmann, I. E. (2008). Design of responsive supply chains under demand uncertainty. Computers and Chemical Engineering , 32, 3090-3111. 
Zondervan, E., Nawaz, M., de Haan, A. B., Woodley, J. M., \& Gani, R. (2011). Optimal design of a multi-product biorefinery system. Computers and Chemical Engineering , 35, $1752-1766$. 


\section{Figure Captions}

Figure 1. A framework for bioprocess optimization under uncertainty

Figure 2. Monte-Carlo technique (adapted from Gernaey, Lantz, Tufvesson, Woodley, \& Sin (2010)).

Figure 3. Extended process flowsheet for the SSCF-C configuration for bioethanol production.

Figure 4. Averaged plant manufacturing cost criteria obtained from Monte-Carlo simulations plotted as a histogram for the 250 parameter samples.

Figure 5. Linear model fit obtained from Monte-Carlo simulations for the manufacturing cost.

Figure 6. Pseudo-code for Monte-Carlo Optimization under Uncertainty.

Figure 7. Extended process flowsheet configurations for bioethanol production: a) SSCF-C_RECY, b) SHCF with double recycle and c) SHCF with single recycle. 